\title{
Evaluation of the Cwm Taf University Health Board Domiciliary Medicines Use Review (Dom-MUR) Service
}

\author{
Lauren Grisley ${ }^{1}$, Abigail Manning ${ }^{1}$, Harry Lee ${ }^{1}$, David McRae ${ }^{2}$, Emma Williams ${ }^{3}$ and Efi Mantzourani ${ }^{1 *}$ \\ ${ }^{1}$ Cardiff School of Pharmacy and Pharmaceutical Sciences, Cardiff University, UK
}

${ }^{2}$ Prince Charles Hospital, UK

${ }^{3}$ Community Pharmacy \& Primary Care, $U K$

Submission: February 03, 2017; Published: March 27, 2017

*Corresponding author: Efi Mantzourani, Cardiff School of Pharmacy and Pharmaceutical Sciences, Cardiff University, UK, Tel: +44-2920-870452; Email: MantzouraniE1@cardiff.ac.uk

\begin{abstract}
The Medicines Use Review (MUR) Service is an Advanced Service in the community pharmacy contract in the United Kingdom (UK). It involves the pharmacist reviewing a patient's use of their medication whose purpose is to improve patient understanding and adherence to medication and reduce medication waste. Since November 2012, the Cwm Taf University Health Board (UHB) in Wales has commissioned a domiciliary MUR (Dom-MUR) service, thereby providing housebound patients with equal access to MURs to those able to visit a community pharmacy. We aimed to identify the types of issues and interventions carried out by pharmacists as part of the Dom-MUR service. A database of Dom-MUR entries from December 2012 - March 2014 was obtained from the UHB. Issues and outcomes arising from Dom-MURs were categorised. Data was quantitatively analysed using Microsoft Excel ${ }^{\circledR}$ and GraphPad Prism $\AA$.

Data from 194 Dom-MURs was included in the database. The mean number of issues identified per patient was 1.96 (SD \pm 1.41 ). The three most commonly identified issues were related to 'Patient Adherence (29\%, $\mathrm{n}=110)$, 'Patient Education/ Monitoring' (21\%, $\mathrm{n}=79$ ) and 'Medication Excess in Home' $(12 \%, n=47)$. The mean number of outcomes per patient was 1.97 (SD \pm 1.48$)$. Of the outcomes, 32\% ( $=122)$ involved the pharmacist contacting the GP surgery i.e. they could not resolve these issues themselves. Issues assigned to 'Issues with Patient's Condition' were statistically less likely to be resolved by the pharmacist. The Cwm Taf UHB Dom-MUR service has the potential to be of value in terms of more appropriate and cost effective care. Developments within community pharmacy, such as access to patients' health records and pharmacist independent prescribing, may benefit this service with the potential for pharmacists to resolve more issues themselves.
\end{abstract}

\section{Introduction}

The Medicines Use Review (MUR) service is an Advanced Service within the National Health Service (NHS) Community Pharmacy Contractual Framework in England and Wales, introduced in 2005 [1]. An MUR involves a pharmacist reviewing a patient's use of their medication and is focused on improving a patient's understanding and adherence to medicines, identifying issues and reducing medication wastage [1]. Adherence to medication for long-term conditions has been described by the World Health Organization (WHO) as "a problem of striking magnitude" [2]. Only 30-40\% of patients are estimated to adhere to their prescribed medication, with poor adherence leading to poor health outcomes and contributing to increased hospital admissions and healthcare costs [2-5].

Within an MUR, pharmacists aim to provide patients with necessary information to improve adherence to their medication. Some evaluations of MURs have identified an increase in medicines' knowledge knowledge of patients who have received reviews and improved confidence in managing their conditions $[6,7]$. However, the evidence that MURs improve health or prevent hospital admissions is ambiguous and it has been disputed whether MURs are worth funding [8-10]. The failure to find evidence of beneficial effects of MURs on these health outcomes has been blamed on the relatively vague criteria for patients to be eligible for review. Vague eligibility criteria, as well as pressure on pharmacists to meet annual employer MUR targets which is argued to often be driven by profit rather than patient need $[11,12]$ is thought to have resulted in many pharmacists conducting reviews on patients who do not need one [11].

Targeted MURs were introduced in December 2011, requiring pharmacists to provide a proportion (currently 70\%) 
of MURs to patients within select target groups. In Wales, these include patients prescribed high-risk, anti-hypertensive or respiratory medications, patients prescribed a medication no longer needed and patients aged 85 years or over prescribed 6 items or more. This ensures that the service is provided to those who will benefit most from it [13]. However, MURs must usually be conducted in a pharmacy consultation room, which is problematic for housebound patients. Telephone MURs are occasionally conducted with housebound patients, but pharmacists are not routinely expected to conduct MURs over the telephone and NHS approval is required each time [14]. Literature regarding telephone MURs is limited with no reports on their value. 'Domiciliary' pharmaceutical services have been described in the literature, commonly referred to as a Pharmacist Domiciliary Visiting Service (PDVS), targeting housebound patients who rely on careers to collect their medicines or on prescription delivery services [15-19]. It has been recognised that these domiciliary services are essential in providing equal access to pharmaceutical care, in line with the founding principles of the NHS, with the core principles of NHS Wales introduce the following statements:

"We care for those with the greatest health need first, making the most effective use of all skills and resources and constantly seeking to fit the care and services we provide to users' needs".

"We strive to improve health and remove inequities by working together with the people of Wales so as to ensure their wellbeing now and in future years and generations" [20].

Housebound patients are a particularly vulnerable demographic - often frail, elderly patients with co-morbidities and an associated increase in poly-pharmacy who also tend to have limited contact with healthcare professionals in general hence there is potential for enhanced benefits from this type of review. Recommendations from the National Service Framework for Older People suggest that patients need support if they are to take medicines as prescribed [21]. It has also been suggested that carrying out reviews in patients' homes may give pharmacists a clearer impression of how patients manage their medication on a daily basis, compared to reviews in consultation rooms or via telephone where pharmacists often have to rely on the patient's word $[22,23]$.

A practice-based audit was carried out in 2010-11 within the Cwm Taf University Health Board (UHB) on patient returned medicines which indicated that a number of patients rarely seen in the pharmacy returned a considerable number of waste medicines. Another audit of 21 pharmacies in the same UHB in 2012 found that over $20 \%$ of dispensed items were delivered, each delivery containing an average of 5.5 items - almost double the average number in collected prescriptions. To investigate the viability of a domiciliary service, consent was gained from the UHB to conduct as many domiciliary visits as possible in one day. Fourteen patients were reviewed in their homes, and the information gathered from these consultations led the UHB to formally introducing a domiciliary MUR service.

The Domiciliary Medicines Use Review (Dom-MUR) service was commissioned by Cwm Taf UHB in November 2012, aiming to provide housebound patients equal access to MURs to those able to visit a pharmacy, ensuring that vulnerable patients are benefitting from their medicines [24]. Fifty-five pharmacies in the UHB were originally commissioned to provide the Dom-MUR service, with a payment of $£ 26$ in addition to the usual $£ 28$ MUR fee. Pharmacists identified eligible patients from their Patient Medication Records (PMR) and were required to confirm that:

The patient was responsible for administering their own medication or depended upon a career

- $\quad$ The patient was in receipt of a prescription delivery service and it was unreasonable for them to travel to a pharmacy-based MUR.

The aim of this study was to identify the types of issues and interventions carried out by pharmacists as part of the Cwm Taf UHB Dom-MUR service.

Methodology

\section{Overview of Study Design}

A secondary analysis of the Dom-MURs database using using Microsoft Excel $®$ and GraphPad Prism $®$.

\section{Ethical Considerations}

Cwm Taf UHB approved this research as a 'service evaluation' and ethical approval from the Cardiff School of Pharmacy and Pharmaceutical Sciences Research Ethics Committee was obtained prior to the study commencing.

\section{Data Collection}

Data collection using paper intervention forms for the DomMURs database was undertaken by pharmacists as they made interventions. During Dom-MURs, pharmacists were required to document all interventions made, even where no actions were identified, and submit a copy of the action plan to the UHB following the review. In collaboration with the Cwm Taf UHB lead investigators, a database with entries from the original MUR documentation completed by pharmacists during DomMURs between December 2012-March 2014 was obtained. The database was reviewed and three main identities were established - issues, outcomes and medication.

\section{Validation Stage}

Categories were assigned to issues and outcomes independently. Regular group discussions to ensure consistency increased the validity of data. The main categories used to assign issues are shown in (Table 1) the categories used to assign outcomes are shown in (Table 2). Medications involved in issues were classified using the chapters of the British National Formulary (BNF) [25]. 
Table 1: Categorization of issues identified in Dom-MURs.

\begin{tabular}{|c|c|}
\hline Main Category & Description \\
\hline 1.1 Lifestyle & $\begin{array}{l}\text { The pharmacist has noted that lifestyle } \\
\text { advice was needed, for example, smoking, } \\
\text { diet, vaccination. }\end{array}$ \\
\hline $\begin{array}{l}\text { 1.2 Patient } \\
\text { Education/ } \\
\text { Monitoring }\end{array}$ & $\begin{array}{l}\text { The pharmacist has noted that the patient } \\
\text { requires education regarding their } \\
\text { medication/ condition, for example storage } \\
\text { of medication, inhaler technique. }\end{array}$ \\
\hline $\begin{array}{c}\text { 1.3 Medication } \\
\text { Assistance Required }\end{array}$ & $\begin{array}{l}\text { The pharmacist has noted that the patient } \\
\text { requires assistance with their medication, } \\
\text { for example, a Monitored Dosage System } \\
\text { (MDS) tray, spacer. }\end{array}$ \\
\hline $\begin{array}{l}\text { 1.4 Patient Adherence } \\
\text { Issues }\end{array}$ & $\begin{array}{l}\text { The pharmacist has noted that the } \\
\text { patient has issues with adherence to their } \\
\text { medication/s. For example, the patient does } \\
\text { not take their medication or does not take it } \\
\text { according to directions prescribed. }\end{array}$ \\
\hline $\begin{array}{l}1.5 \text { Issues with } \\
\text { Repeat Medication/ } \\
\text { Prescription }\end{array}$ & $\begin{array}{l}\text { The pharmacist has noted an issue with the } \\
\text { patients repeat medication or prescription, } \\
\text { for example, medication not synchronised, } \\
\text { insufficient monthly quantity. }\end{array}$ \\
\hline $\begin{array}{l}1.6 \text { Issues with } \\
\text { Patient's Condition }\end{array}$ & $\begin{array}{l}\text { The pharmacist has noted that there is } \\
\text { an issue with the patient's condition. } \\
\text { For example, the patient's symptoms are } \\
\text { uncontrolled/ worsening or a new condition } \\
\text { is suspected. }\end{array}$ \\
\hline $\begin{array}{l}\text { 1.7 Issues with Use of } \\
\text { Medication/ } \\
\text { Devices }\end{array}$ & $\begin{array}{l}\text { The pharmacist has noted that the patient } \\
\text { currently experiences difficulty using their } \\
\text { medication or device, for example due to } \\
\text { packaging, formulation. }\end{array}$ \\
\hline $\begin{array}{l}\text { 1.8 Assessment } \\
\text { Required }\end{array}$ & $\begin{array}{l}\text { The pharmacist has noted that the patient } \\
\text { requires an assessment, for example, an eye } \\
\text { check. }\end{array}$ \\
\hline $\begin{array}{l}1.9 \text { Issues with } \\
\text { Continuity of Care }\end{array}$ & $\begin{array}{l}\text { The pharmacist has noted that there is an } \\
\text { issue with continuation of a patient's current } \\
\text { care, for example incomplete PMRs, unclear } \\
\text { changes in treatment due to a transfer } \\
\text { between care settings. }\end{array}$ \\
\hline $\begin{array}{l}\text { 1.10 Communication/ } \\
\text { Clarification } \\
\text { with General } \\
\text { Practitioner (GP) } \\
\text { Needed }\end{array}$ & $\begin{array}{l}\text { The pharmacist has noted that there is an } \\
\text { issue regarding the clarity of a patient's } \\
\text { current treatment, for example duration of } \\
\text { treatment, dose, indication. }\end{array}$ \\
\hline $\begin{array}{l}1.11 \text { Medication } \\
\text { Excess in Home }\end{array}$ & $\begin{array}{l}\text { The pharmacist has recorded that the } \\
\text { patient has medication excess in the home } \\
\text { that needs to be removed and/ or controlled. }\end{array}$ \\
\hline 1.12 No Issues & $\begin{array}{l}\text { The pharmacist has carried out appropriate } \\
\text { checks during the Dom-MUR but no further } \\
\text { issues were recorded, or no issues were } \\
\text { recorded with no checks carried out by } \\
\text { the pharmacist during the Dom-MUR } \\
\text { documented. }\end{array}$ \\
\hline
\end{tabular}

Table 2: Categorization of outcomes.

\begin{tabular}{|c|c|c|}
\hline Main Category & Sub-Category & Description \\
\hline \multirow{2}{*}{$\begin{array}{l}\text { 2.1. Pharmacist- } \\
\text { Led } \\
\text { Outcomes }\end{array}$} & $\begin{array}{l}\text { 2.1.1. Pharmacist } \\
\text { Contacted } \\
\text { GP Surgery }\end{array}$ & $\begin{array}{c}\text { The pharmacist } \\
\text { contacted the GP } \\
\text { surgery to resolve the } \\
\text { issue. }\end{array}$ \\
\hline & $\begin{array}{l}\text { 2.1.2. Pharmacist } \\
\text { Resolved }\end{array}$ & $\begin{array}{l}\text { The pharmacist was } \\
\text { able to resolve the issue } \\
\text { themselves, either in } \\
\text { the Dom-MUR or back } \\
\text { in the pharmacy. }\end{array}$ \\
\hline $\begin{array}{l}\text { 2.2. Patient-Led } \\
\text { Outcomes }\end{array}$ & $\begin{array}{l}\text { 2.2.1. Healthcare } \\
\text { Professional (HCP) } \\
\text { Appointment } \\
\text { Recommended }\end{array}$ & $\begin{array}{l}\text { The pharmacist } \\
\text { recommended that } \\
\text { the patient make an } \\
\text { appointment with a } \\
\text { healthcare professional } \\
\text { (GP, optician, nurse } \\
\text { etc.) but did not make } \\
\text { the appointment on the } \\
\text { patient's behalf. }\end{array}$ \\
\hline \multirow{2}{*}{$\begin{array}{l}\text { 2.3. No Outcomes } \\
\text { Documented }\end{array}$} & $\begin{array}{c}\text { 2.3.1. No Issue } \\
\text { Identified Hence No } \\
\text { Outcome }\end{array}$ & $\begin{array}{c}\text { The pharmacist } \\
\text { identified no issue } \\
\text { hence there was no } \\
\text { outcome. }\end{array}$ \\
\hline & $\begin{array}{l}\text { 2.3.2. Issue Identified } \\
\text { But No Definite } \\
\text { Outcome }\end{array}$ & $\begin{array}{c}\text { The pharmacist } \\
\text { identified an issue } \\
\text { but no outcome was } \\
\text { recorded. }\end{array}$ \\
\hline
\end{tabular}

\section{Data Input}

Qualitative data collected from original MUR documentation was input into a Microsoft Excel ${ }^{\circledR}$ database by the Cwm Taf UHB lead investigators prior to the study commencing. The data included: a reference number for each patient, the issue/s recorded by the pharmacist, whether the issue was to be considered by the GP, pharmacist, patient or 'not specified' and the outcomes.

Some rows (i.e. entries) on the original database contained multiple issues or outcomes and could be assigned to more than one category. Patients often had multiple entries in the database. Some patients had no issues recorded during their reviews, whereas some patients had issues recorded as well as appropriate checks (compliance etc.) documented by the pharmacist with no further issues. Tally charts were produced to display the assignment of issues, outcomes and medication to categories (Appendix 6).

To aid descriptive statistical analysis, a second Microsoft Excel $\AA$ spreadsheet was produced with the reference number of the patient, the number of issues per patient, the number of outcomes per patient, the categories of issues identified (as a number e.g. 1.1.1.) and the categories of outcomes (as a number e.g. 2.1.1.). BNF chapters (as a number e.g. 2) and BNF classes (in words e.g. Statins) were assigned to issues where medication was named.

Data was also input into GraphPad Prism®. This data included the issues identified per category and whether pharmacists 
could resolve the issues within those categories themselves or not $(1=$ the pharmacist resolved the issue themselves, $2=$ the pharmacist did not resolve the issue themselves).

\section{Analysis}

Microsoft Excel ${ }^{\circledR}$ was used to calculate means, standard deviations and modes for the number of issues and outcomes per patient, as well as percentages of issue and outcome categories. Excel ${ }^{\circledR}$ was also used to analyze medication data, including a ranked list of medication categorized by BNF chapter. Graphs and charts displaying data were produced using Excel@. GraphPad Prism ${ }^{\circledR}$ was used to perform a one-way ANOVA with Tukey's post-hoc test to check for statistically significant differences in the proportion of issues within different categories that pharmacists were able to resolve themselves.

\section{Results}

\section{Issues per patient}

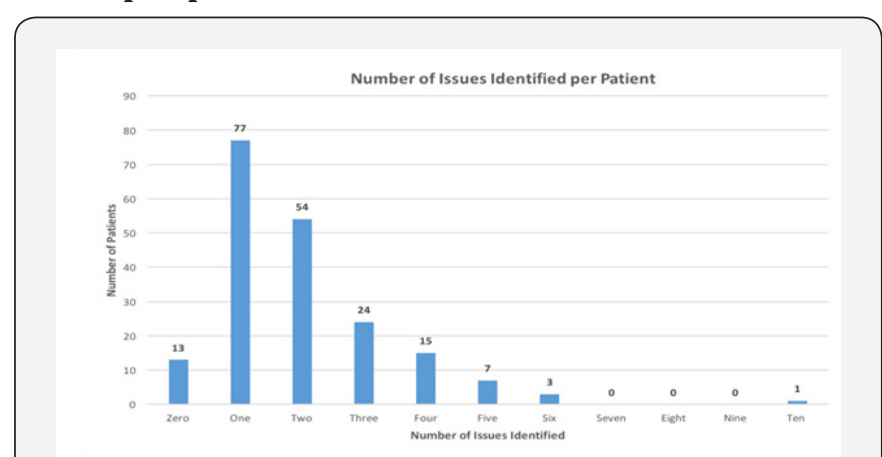

Figure 1: Number of issues identified per patient

Data from Dom-MURs with 194 patients was included within the database. (Figure 1) shows the number of issues identified per patient. Thirteen patients $(6.7 \%)$ had no issues identified during their review. The remaining 181 patients had at least one issue identified. The mean number of issues identified per patient was 1.96 (SD 1.41). The most common number of issues identified per patient was one issue $(39.69 \%, \mathrm{n}=77)$. One patient had 10 issues, which was the largest number of issues identified per patient. Of the 13 patients who had no issues identified at all during their review, 4 were documented to have had appropriate checks carried out during the MUR (adherence etc.). The remaining 9 had no checks documented by the pharmacist hence it was impossible to determine whether the pharmacist had checked the patient's adherence, understanding of medicines etc.

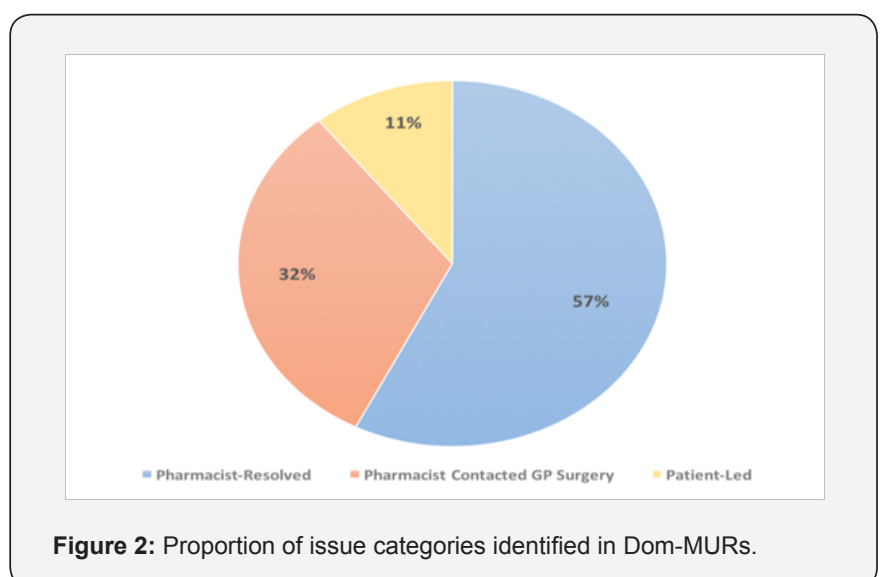

\section{Issue categories identified}

The database contained a total of 380 issues, with 11 categories of issues identified. (Figure 2) shows the proportion of issue categories identified in Dom-MURs. The three most commonly identified issues within the Dom-MURs were related to 'Patient Adherence' (29\%, $\mathrm{n}=110)$, 'Patient Education/ Monitoring' (21\%, $n=79)$ and 'Medication Excess in Home' (12\%, $\mathrm{n}=47)$.

A further 28 entries fell into the category '1.12. No Issues'. Thirteen of these related to patients who had no issues identified during their MUR, as previously stated. The remaining 15 entries related to patients who did have other issues recorded, with 'no issue' referring to respective checks also documented (adherence etc.).

\section{BNF classification of medication}

Of the total issues, $65.79 \%(n=250)$ had at least one named medication related. Some issues had multiple medications named. The total number of named medications related to issues was 283. (Table 3) shows a ranked list of the most common types of named medicines, categorized by BNF chapter.

Table 3: Categorization of medications by BNF chapter.

\begin{tabular}{|c|c|c|c|c|}
\hline Rank & BNF Category & $\begin{array}{c}\text { BNF } \\
\text { Chapter }\end{array}$ & $\begin{array}{c}\text { Number of } \\
\text { Drugs (\% of } \\
\text { total) }\end{array}$ & Most common class of drug within the chapter \\
\hline 1 & Cardiovascular System & 2 & $65(23.0)$ & Antiplatelet Drugs and Statins \\
\hline 1 & Respiratory System & 3 & $65(23.0)$ & Inhaled Corticosteroids \\
\hline 3 & Nervous System & 4 & $53(18.7)$ & Opioid Analgesics \\
\hline 4 & Gastro-intestinal System & 1 & $35(12.5)$ & Proton Pump Inhibitors \\
\hline 5 & Endocrine System & 6 & $19(6.7)$ & Vitamin D and Analogues \\
\hline 6 & Blood and Nutrition & 9 & $17(6.0)$ & NSAIDs \\
\hline 7 & Musculoskeletal System & 10 & $9(3.2)$ & Alpha-adrenoceptor Blockers \\
\hline 8 & Genito-Urinary System & 7 & $4(1.4)$ & \\
\hline
\end{tabular}




\section{Global Journal of Pharmacy \& Pharmaceutical Sciences}

\begin{tabular}{|c|c|c|c|c|}
\hline 8 & Eye & 11 & $4(1.4)$ & Ocular Lubricants \\
\hline 10 & Infection & 5 & $3(1.0)$ & $\begin{array}{c}\text { Antibacterials (Penicillins) AND Antiprotozoals AND } \\
\text { Nucleoside Analogues (Antivirals) }\end{array}$ \\
\hline 10 & Skin & 13 & $3(1.0)$ & Emollients \\
\hline 10 & Borderline Substances & A2 & $3(1.0)$ & Advanced Wound Dressings \\
\hline 13 & Ear, Nose and Oropharynx & 12 & $2(0.7)$ & $1(0.4)$ \\
\hline 14 & $\begin{array}{c}\text { Wound Management Products } \\
\text { and Elasticated Garments }\end{array}$ & A4 & 283 \\
\hline & Total Number of Medications & \\
\hline
\end{tabular}

Medication could only be included in figures if the name of the medication was specifically stated. For example, 'inhalers', whilst referring to a medicine, could not be classified. Cardiovascular and respiratory medications were most commonly related to issues. Antiplatelet drugs and statins were the most common cardiovascular medications. The most common issue related to both antiplatelet drugs and statins was non-adherence $(46.2 \%$, $\mathrm{n}=6$ and $69.2 \%, \mathrm{n}=9$ respectively). Inhaled corticosteroids were the most common respiratory medication. The most common issue related to inhale corticosteroids was patient education: inhaler technique $(40.7 \%, \mathrm{n}=11)$.

\section{Outcomes}

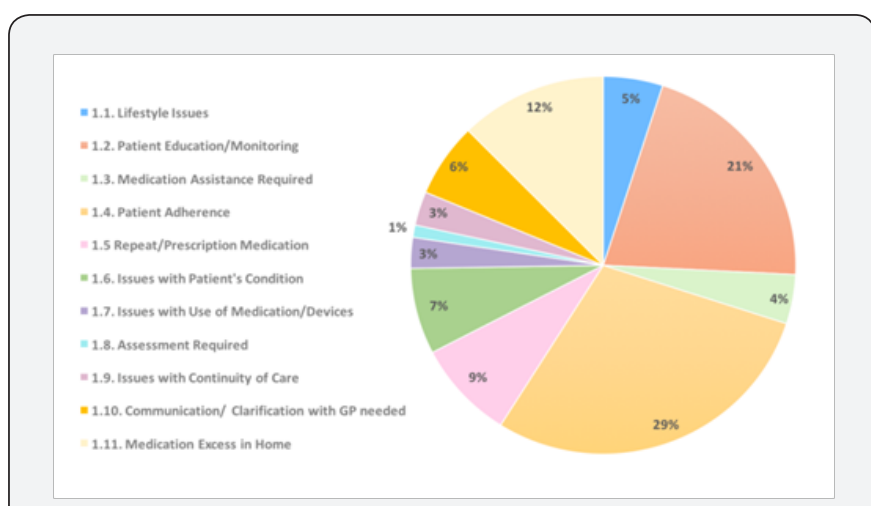

Figure 3: Proportion of outcome types documented in Dom-MURs.

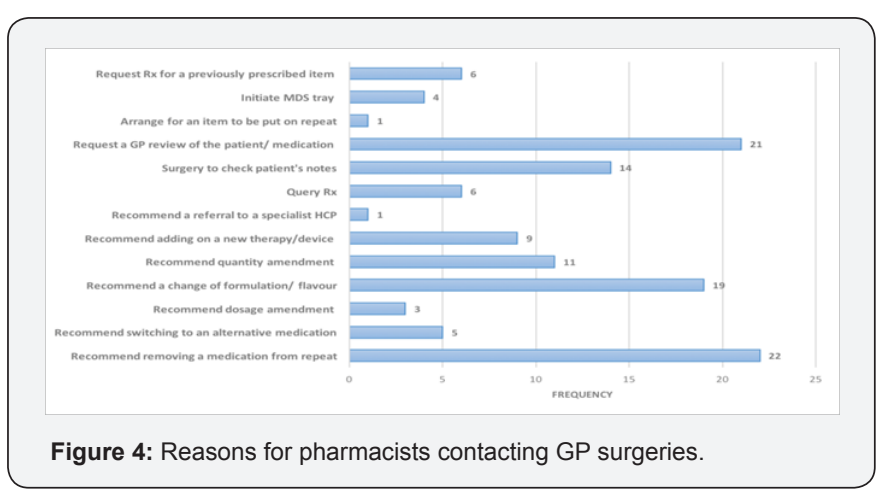

The database contained a total of 383 outcomes documented by pharmacists. Some issues had more than one outcome documented. (Figure 3) shows the proportion of outcome types documented. The mean number of outcomes per patient was
1.97 (SD \pm 1.48$)$. Fifty-seven percent $(\mathrm{n}=220)$ of outcomes were pharmacist-resolved, either during Dom-MURs or back in the pharmacy. Thirty-two percent $(n=122)$ of outcomes involved pharmacists contacting the GP surgery i.e. they could not resolve these issues themselves. (Figure 4) shows a breakdown of reasons for pharmacists contacting the GP surgery.

Common reasons pharmacists contacted the GP surgery included: to remove an item from repeat $(18.03 \%, \mathrm{n}=22)$ ), to request the GP to review the patient/ medication $(17.21 \%$, $\mathrm{n}=21)$, to recommend changing formulation/ flavour $(15.6 \%$, $\mathrm{n}=19)$, to amend monthly medication quantity $(9.02 \%, \mathrm{n}=11)$ and to check patient's notes $(11.5 \% \mathrm{n}=14)$.A further $11 \%(\mathrm{n}=41)$ of outcomes were patient-led, where pharmacists recommended that patients make appointments with healthcare professionals but did not do this on their behalf. There were 7 issues identified by pharmacists with no definite outcomes documented hence it was unclear what, if anything, had been recommended to resolve these issues. Figure 5 shows a comparison of outcome types between categories of issues, taking into account the 7 issues with no definite outcomes recorded.

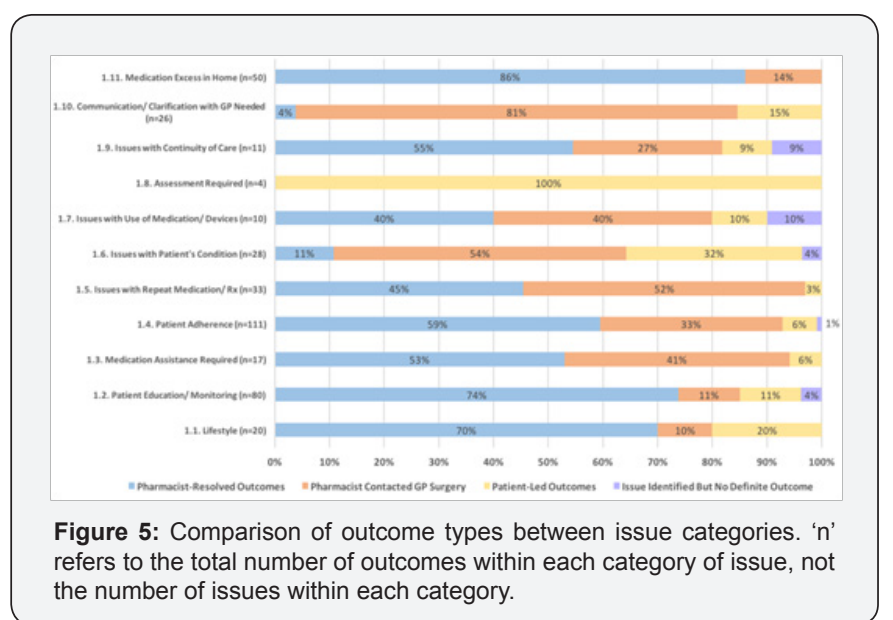

The proportion of pharmacist-resolved outcomes was greatest in '1.11. Medication Excess in Home'. The proportion of outcomes where pharmacists contacted the GP surgery was greatest in '1.10. Communication/ Clarification with GP Needed'. All outcomes within '1.8. Assessment required' were patient-led, as pharmacists recommended all patients within this category make appointments with an optician. 


\section{Statistical analysis}

To check whether there were statistically significant differences in the types of issues that pharmacists were able to resolve themselves, p-values were calculated using a one-way ANOVA with Tukey's post-hoc test. The category '1.8. Assessment required' was omitted as it contained a low number of issues $(n=4)$. One-way ANOVA showed there was a highly significant difference in the pharmacists' ability to resolve different types of issues overall $(\mathrm{p}<0.0001)$.

To compare between different categories of issues, Tukey's post-hoc test was utilized. Three groups were found to be statistically significant $(\mathrm{p}<0.05)$ to the rest: Issues with Patient's Condition, Communication/Clarification with GP needed and Medication Excess in Home.

In more detail significant differences were found between '1.6. Issues with Patient's Condition' and '1.1. Lifestyle'; '1.2. Patient Education/ Monitoring', '1.4. Patient Adherence" AND '1.11. Medication Excess in Home'; '1.10. Communication/ Clarification with GP Needed' and '1.1. Lifestyle'; 1.2. 'Patient Education/ Monitoring', '1.4. Patient Adherence" AND '1.11. Medication Excess in Home'; '1.10. Communication/ Clarification with GP needed' and '1.3. Medication Assistance Required' AND '1.5. Issues with Repeat Medication/ Prescription'; '1.11. Medication Excess in Home' and '1.4. Patient Adherence' AND '1.5. Issues with Repeat Medication/ Prescription'.

Statistical analysis highlights there were types of issues that pharmacists were less likely to resolve themselves, in particular issues in '1.10. Communication/ Clarification with GP Needed' and '1.6. Issues with Patient's Condition'.

\section{Discussion}

Few domiciliary MUR services are commissioned in the UK, with little published data regarding the types of issues identified and interventions made. This is the first study to identify the types of issues and interventions carried out by pharmacists as part of a Dom-MUR service. Issues and outcomes were categorised and quantified, with medication classified according to the BNF.

The vast majority of Dom-MURs identified at least one issue. The mean number of outcomes per Dom-MUR was 1.97, approximately three times higher than the mean number of outcomes per pharmacy-based MUR in the UHB (E. Williams, personal communication). This suggests that the service targets appropriate patients who are in most need of medication reviews, which is the predominant rationale for commissioning this service. This may have been aided by pharmacists being able to see how patients manage their medication in their homes. Patients may also have felt more comfortable being reviewed in their own homes, resulting in a more open conversation hence more issues being identified.

Most research regarding MURs focus on the process rather than content and outcomes of reviews. The three main issues identified tend to be the focus of MURs. Twenty-nine percent of issues were related to patient non-adherence with $59 \%$ resolved by pharmacists. It is unsurprising that non-adherence was the most common issue identified. As housebound patients tend to have less contact with healthcare professionals, there is less opportunity to encourage these patients to take their medications as prescribed hence domiciliary visits from pharmacists are potentially valuable. However, a Cochrane review on interventions to improve adherence identified little published evidence on what works best [26]. Although pharmacists identified and may have 'resolved' the issue by giving advice, this does not mean that patients' long-term adherence has improved. Follow-up studies of these patients over time would indicate whether adherence issues have actually been resolved long-term.

Medication wastage is estimated to cost NHS Wales up to $£ 50$ million annually [27]. Eighty-six percent of medication excess issues identified were resolved by pharmacists which is important as intervening with medication excess helps reduce further wastage and NHS costs. This is likely to have been helped by pharmacists being able to see expired medicines and unused supplies unlike pharmacy-based MURs where patients often bring samples of what they can carry hence these issues can often go unnoticed [5].

Cardiovascular and respiratory medications were most commonly related to issues, similar to a larger pharmacy-based study of 1948 MURs which found that cardiovascular medications accounted for the largest number of medications needing action [11]. A large proportion of respiratory medication issues were related to inappropriate inhaler technique, all of which resulted in education by pharmacists during reviews which is important as inadequate technique leads to poor adherence and suboptimal therapy $[28,29]$. These medication groups are part of the targeted MUR eligibility criteria therefore the Dom-MUR service can potentially support the provision of targeted MURs.

A large proportion of issues, in particular regarding lifestyle, patient education and medication excess, were resolved by pharmacists themselves. However, there were issues that pharmacists were statistically less likely to resolve themselves, with $32 \%$ of outcomes involving pharmacists contacting GP surgeries. Reports in the literature comment that many GPs query the benefit of MURs, in particular the paperwork involved and the types of recommendations made by pharmacists [30]. A pharmacy-based MUR study found that a considerable number of recommendations were not subsequently auctioned by GPs [11]. Follow-up information of this kind was not available in this project. While contacting the GP is inevitable in certain situations, pharmacists should resolve as many issues as possible to relieve the burden on GP surgeries, with the Royal Pharmaceutical Society (RPS) stating:

"No GP should routinely be undertaking any activity which could, just as appropriately, be undertaken by an advanced 
practice nurse, a clinical pharmacist or an advanced practitioner paramedic" [31].

The role of the pharmacist is expanding, with increasing prevalence of pharmacists in GP surgeries and the Common Ailments Service introduced in Cwm Taf UHB to cut pressures on GPs [32]. Of the situations where pharmacists contacted the GP surgery, $11.5 \%$ were to check patients' health records, for example to check indications of medication. NHS England has supported community pharmacies in gaining access to Summary Care Records (SCR), enabling pharmacists to support patients with better-informed care and reducing the need to contact GPs [33,34]. An evidence review from MURs published in 2010 found that the quality of recommendations made by pharmacists improves when pharmacists have more patient information [35]. It is hoped in the near future a similar set-up will be implemented for community pharmacists in Wales to access GP records, with the RPS stating:

"In the interest of safe and effective patient care, all pharmacists involved in an individual's care should have appropriate read and write access to the Welsh GP record". This may aid the Dom-MUR service, reducing the need for pharmacists to contact GP surgeries to check patients' records. The RPS is also keen for pharmacists to fully utilize their expertise in supporting patients with long-term conditions, and encourage opportunities for pharmacists to become prescribers [31]. The 2016 Murray Review has called for a redesign of MURs, utilizing pharmacist independent prescribers (PIPs) to implement medicines optimization [36]. PIPs may be beneficial in developing the Dom-MUR service, with potential to further reduce the number of issues passed on to GPs. For example, $15.6 \%$ of reasons for contacting GPs were to amend medication formulation/ flavor, which could have been resolved by PIPs.

However, the potential of PIPs has not been exploited especially in the community sector. Limited funding and access to patient records are recognised as barriers [37], but access to the Welsh GP record and emphasis on pharmacists' abilities to help with current pressures on GP surgeries may increase the prevalence of community pharmacist prescribing, potentially enhancing the Dom-MUR service. It is important to note however that PIPs should only prescribe within their competence in a therapeutic area. This may affect how patients are targeted for domiciliary visits in the UHB, with PIPs targeting patients who have clinical conditions within their therapeutic area.

\section{Study limitations}

This study relies on completeness of MUR documentation by pharmacists, who may have addressed issues during reviews which they failed to document. If so, this study would underestimate the overall number of issues identified. It is recognised in the literature that pharmacists may priorities issues to address in reviews, leaving less important issues for follow-up appointments [38].
The database, comprised of faithful transcriptions of original MUR documentation, was often vague. Some pharmacists were less thorough in their documentation, making categorization of issues difficult especially as many medications were not specifically named. Lack of uniformity between pharmacists in documenting MURs has been recognised in the literature. Categorization of issues introduced bias to the study due to their subjective nature. The vast majority of issues assigned to '1.10. Clarification/ Communication with GP Needed' could not be resolved by pharmacists themselves due to the nature of the issues. These issues could not be assigned elsewhere, but it could be argued that this category is an outcome rather than an issue. This is a unique study hence a published classification system to analyzed Dom-MURs was not available. Classification systems to analyzed pharmacy-based MURs have been published [38], but it was deemed that utilizing them would lead to issues being assigned to inappropriate categories. Discontinuation of domiciliary services is common [19]. A similar domiciliary service was piloted and subsequently withdrawn in Abertawe Bro Morgannwg UHB due to logistical difficulties of pharmacists leaving the pharmacy to conduct domiciliary visits (Morris A. 2017. Personal communication). It would be critical to also gather the views of pharmacists undertaking the Dom-MUR service to identify any barriers they perceive in delivering the service.

\section{Conclusion}

The Cwm Taf Dom-MUR service targets appropriate patients in need of medication reviews and this study shows that the service has the potential to be of value in helping housebound patients benefit from their medicines. Future developments in community pharmacy, such as increasing prevalence of pharmacist independent prescribing and access to patients' health records, may further the potential to utilize pharmacists' expertise and reduce the burden on GP surgeries to resolve issues identified. The opinions of pharmacists who conduct the service still need to be explored to supplement quantitative data and provide a wider evaluation of the service.

\section{References}

1. http://psnc.org.uk/services-commissioning/advanced-services/ murs/murs-the-basics/

2. World Health Organisation (2003) Adherence to long term therapies: evidence for action. World Health Organisation, Geneva, Switzerland, pp 1-209.

3. Cushing A, Metcalfe R (2007) Optimizing medicines management: From compliance to concordance. Ther Clin Risk Manag 3(6): 10471058.

4. Blenkinsopp A, Bond C, Raynor DK (2012) Medication Reviews. Br J Clin Pharmacol 74(4): 573-580.

5. Petty D (2008) Can medicines management services reduce hospital admissions?. Pharm J 280: 123-126.

6. Youssef S, Hussain S, Upton D (2010) Do patients perceive any benefit from medicines use reviews offered to them in community pharmacies? Pharm J 284: 165-166. 
7. Twigg MJ, Bhattacharya D, Clark A, Patel R, Rogers H, et al. (2016) What do patients need to know? A study to assess patients' satisfaction with information about medicines. Int J Pharm Pract 24(4): 229-236.

8. Holland R, Smith R, Harvey I (2006) Where now for pharmacist led medication review? J Epidemiol Community Health 60(2): 92-93.

9. Pacini M, Smith RD, Wilson ECF, Holland R (2007) Homebased medication review in older people: is it cost-effective? Pharmacoeconomics 25(2): 171-180.

10. Wright D (2016) A rapid review of evidence regarding clinical services commissioned from community pharmacies pp 1-50.

11. Wilcock M, Harding G (2008) What do pharmacists think of MURs and do they change prescribed medication? The Pharmaceutical Journal 281: 163-167.

12. Sukkar E (2013) Have medicines use reviews come to represent profit over patient care? The Pharmaceutical Journal 291: 137.

13. Goodway R (2015) Community pharmacy contractual framework changes. Cardiff: Community Pharmacy Wales.

14. NHS Employers (2013) Guidance on the medicines use review service. Leeds: NHS Employers.

15. Schneider J, Barber N (1996) Provision of a domiciliary service by community pharmacists International Journal of Pharmacy Practice 4(1): 19-24.

16. Holland R, Lenaghan E, Harvey I, Smith R, Shepstone L, et al. (2005) Does home based medication review keep older people out of hospital? The HOMER randomised controlled trial. BMJ 330(7486): 293.

17. Foulsham R, Goodyer L (1999) Referrals made by different health care professionals to community pharmacists for domiciliary visits. International Journal of Pharmacy Practice 7(2): 86-91.

18. Begley S, Williamson V, Hodges N, Livingstone C (1993) Provision of domiciliary pharmacy services by community pharmacists. Pharm J 251: 32

19. Bhattacharya D, Wirght DJ, Purvis JR (2008) Pharmacist domiciliary visiting in England: identifying the characteristics associated with continuation. Pharm World Sci 30(1): 9-16.

20. NHS Wales. The core principles of NHS Wales. Cardiff: NHS Wales.

21. Department of Health (2001) Medicines and older people: implementing medicines-related aspects of the NSF for older people. London: Department of Health.

22. Dilks S, Ian N (2008) Managing patients at home-as a domiciliary pharmacist. Hospital Pharmacist 15: 135-137.

This work is licensed under Creative Commons Attribution 4.0 License DOI: 10.19080/GJPPS.2017.01.555567
23. Law R, Chalmers C (1976) Medicines and elderly people: a general practice survey. BMJ 1(6009): 565-568.

24. Braun V, Clarke V (2013) Successful qualitative research: a practical guide for beginners. London: Sage pp 1-23.

25. Joint Formulary Committee (2016) British National Formulary. In: 71 (Edn), London: BMJ Group and Pharmaceutical Press.

26. Nieuwlaat R, Wilczynski N, Navarro T, Hobson N, Jeffery R, et al. (2014) Interventions for enhancing medication adherence. Cochrane Database Syst Rev 20(11): CD000011.

27. Baker D (2014) Service Director for Pharmacy and Medicines Management. Agenda item 2.5 -update on medicines waste campaign and benchmarking of drugs spend. Cardiff: Cardiff and Vale University Health Board pp 2-4.

28. Anna M (2016) How to help patients optimise their inhaler technique. Pharm J 297(7891).

29. Darbà J, Ramírez G, Sicras A, García-Bujalance L, Torvinen S, et al. (2016) Identification of factors involved in medication compliance: incorrect inhaler technique of asthma treatment leads to poor compliance. Patient Prefer Adherence 10: 135-145.

30. Stoate H (2006) Why many GPs ignore MUR forms. Prescribing and Medicines management 277: PM1.

31. Royal Pharmaceutical Society Wales (2016). Improving care for people with long term conditions. Cardiff: Royal Pharmaceutical Society Wales.

32. Cwm Taf University Health Board (2016) New pharmacy service now offered to patients across Rhondda. Abercynon: Cwm Taf University Health Board.

33.NHS Digital (2015) Summary Care Record rolled out to community pharmacists. Leeds: NHS Digital.

34.Andalo D, Sukkar E (2015) Risks and benefits of pharmacists accessing patients' summary care records. Pharm J 295: (7870).

35. Anne H (2010) Pharmacist-led medication review for older people in the community setting. Cardiff: Public Health Wales pp1-37.

36. Richard M (2017) Community pharmacy clinical services review. Leeds: NHS England.

37. Cope LC (2013) Non-medical prescribing - successful models in community pharmacy [PhD thesis]. Manchester: The University of Manchester.

38. Krska J, Avery AJ (2007) Evaluation of medication reviews conducted by community pharmacists: a quantitative analysis of documented issues and recommendations. Br J Clin Pharmacol 65(3): 386-396.

Your next submission with Juniper Publishers will reach you the below assets

- Quality Editorial service

- Swift Peer Review

- Reprints availability

- E-prints Service

- Manuscript Podcast for convenient understanding

- Global attainment for your research

- Manuscript accessibility in different formats ( Pdf, E-pub, Full Text, Audio)

- Unceasing customer service

Track the below URL for one-step submission

https://juniperpublishers.com/online-submission.php 